\title{
CONSIDERAÇÕES SOBRE A CONSTITUILCÃO DO SUJEITO DO CUIDADO DE SI NO PENSAMENTO DE MICHEL FOUCAULT
}

CONSIDERATIONS REGARDING THE CONSTITUTION OF SUBJECT OF THE CARE OF THE SELF AT THE THOUGHT OF MICHEL FOUCAULT

João Paulo Ayub da Fonseca*

RESUMO - O texto pretende discutir a maneira como Foucault trabalha o problema da constituição do sujeito do cuidado de si - tema que tomou conta de seus últimos livros, cursos, entrevistas e conferências. A problematização deste sujeito e das "técnicas de si" que o constitui surgem na obra do autor a partir do momento em que Foucault reorienta as suas pesquisas sobre as relações de poder ao final dos anos 70, dando início às investigações sobre as formas de governar (governo dos outros). Procura-se mostrar que o deslocamento operado pelo autor passa necessariamente por uma problematização das condições de possibilidade a partir das quais as relações de poder, em sua modalidade de "ações sobre ações", tornam-se possíveis. A liberdade como condição de possibilidade das relações de poder surge na obra de Foucault ao mesmo tempo em que a investigação sobre as "técnicas de si" descortinam a formação de sujeitos éticos.

PALAVRAS-CHAVE - Michel Foucault, cuidado de si, subjetivação, sujeito, liberdade.

ABSTRACT - The present text aims to discuss how Foucault works out the problem of the constitution of the subject of the care of the self - a theme which has filled his last books, courses, interviews and conferences. The problematizing of this "subject", and of the "techniques of the self" which constitute it, comes up in Foucault's work in the moment he re-thinks his researches about the concept of power, at late 70's. This re-orientation gives birth to investigations

* Doutorando em Ciências Sociais pela Universidade Estadual de Campinas. E-mail: $<$ joaoayub@gmail.com>.

\begin{tabular}{|l|l|l|l|l|l|}
\hline Veritas & Porto Alegre & v. 57 & n. 1 & jan./abr. 2012 & p. 143-152 \\
\hline
\end{tabular}


concerning the forms of government (government of others). This text aims to show that this re-orientation performed by Foucault has necessarily to do with the problematization of the conditions of possibility from which arises the relationships of power, specifically the "actions over actions". Freedom, as the condition of possibility for the relationships of power, arises in Foucault's work at the same time in which the research concerning the "techniques of the self" uncurtains the formation of ethical subjects.

KEYWORDS - Michel Foucault, care of the self, subjectivation, subject, freedom

\section{Introdução}

Pode-se afirmar que o problema que gira em torno da constituição do sujeito percorre todo o trabalho de Foucault. Ora remetido às práticas de saber, ora às relações de poder e, por último, através das práticas de si, é o sujeito (ou a subjetividade) como processo histórico um dos principais alvos das análises do autor, senão o principal, como ele mesmo o afirma num dos momentos em que lança um olhar retrospectivo sobre o próprio trabalho (FOUCAULT, 1982, p. 208).

Este texto pretende discutir a maneira como Foucault trabalha o problema da constituição do sujeito do cuidado de si, tema que tomou conta de seus últimos livros, cursos, entrevistas e conferências. Para tal, chamar-se-á a atenção para as condições de possibilidade da emergência histórica desse sujeito. Sustenta-se que tais condições obrigaram Foucault a lançar mão de uma categoria que, em seu pensamento, configura-se como uma espécie de fundamento a priori: a liberdade. Um pequeno texto publicado, em 1982, com o título O sujeito e o poder é bastante esclarecedor da importância dada pelo autor à necessidade de se tratar de sujeitos livres quando se tem em mente a possibilidade de estabelecer uma relação de poder e, ainda, quando se considera a possibilidade de formação e transformação de sujeitos éticos.

A partir da leitura de Deleuze sobre Foucault e da discussão que o próprio Foucault desenvolveu em seu curso proferido em 1982 no Collège de France sobre o tema da hermenêutica do sujeito, dois objetivos principais serão buscados ao longo do texto: 1) mostrar como e porque o tema da liberdade aparece como um deslocamento no conjunto da obra do autor, principalmente quando se considera o conjunto dos trabalhos desenvolvidos até a metade da década de 70, quando se desenha a chamada "analítica do poder", e; 2) explorar as implicações deste deslocamento na medida em que descortina a ética como um novo campo de reflexão no pensamento de Foucault. 


\section{A subjetivação como "terceira dimensão" do pensamento de Foucault}

Em suas Conversações, o filósofo francês Gilles Deleuze, repetidas vezes, afirma ser uma "idiotice" atribuir à filosofia de Foucault um retorno à Teoria do Sujeito. Segundo o filósofo francês, Foucault nunca se preocupou com tal Teoria e, em definitivo, não a fez, pois antes de tratar de um sujeito a-histórico, dotado de identidade e interioridade transcendentes, o que ele fez em seus trabalhos foi estudar processos históricos que, ao se efetivarem como acontecimentos irredutíveis a unidades metafísicas que apontam para a unidade do sujeito tal qual o sujeito racional cartesiano, desconstroem qualquer possibilidade de se estabelecer identidades a priori. A noção de corpo que a obra de Foucault legou-nos testemunha a multiplicidade de composições de forças que atravessam os sujeitos e constituem-nos em planos de produção de subjetividades: "O corpo: superfície de inscrição dos acontecimentos (enquanto que a linguagem os marca e as ideias os dissolvem), lugar de dissociação do EU (que supõe a quimera de uma unidade substancial), volume em perpétua pulverização" (FOUCAULT, 1979, p. 22).

Observa-se em Foucault, portanto, antes do Sujeito, processos de subjetivação e de assujeitamento, sendo o primeiro constituído pelas linhas de força que os indivíduos fazem dobrar sobre si mesmos e o segundo pelas composições de forças conjugadas nos dispositivos de poder-saber. Segundo Deleuze,

Foucault não emprega a palavra sujeito como pessoa ou forma de identidade, mas os termos 'subjetivação', no sentido de processo, e 'Si', no sentido de relação (relação a si). E do que se trata? Trata-se de uma relação da força consigo (ao passo que o poder era a relação da força com outras forças), trata-se de uma 'dobra' da força. Segundo a maneira de dobrar a linha de força, trata-se da constituição de modos de existência, ou da invenção de possibilidades de vida que também dizem respeito à morte, a nossas relações com a morte: não a existência como sujeito, mas como obra de arte. Trata-se de inventar modos de existência, segundo regras facultativas, capazes de resistir ao poder bem como se furtar ao saber, mesmo se o saber tenta penetrá-los e o poder tenta apropriar-se deles. (1992, p. 116).

Ao lado das pesquisas sobre o poder e o saber, nas quais Foucault concebe o sujeito como o produto passivo das técnicas de dominação, o trabalho sobre a subjetivação compõe, de acordo com Deleuze, uma "terceira dimensão". A primeira e a segunda dimensão, as do saber e do poder, respectivamente, não ajudam Foucault a resolver os problemas referentes às possibilidades de resistência frente aos modos 
de assujeitamento. Para Deleuze, por mais que Foucault trabalhe com a ideia de "pontos de resistência" quando analisa as relações de poder e saber, ela não o permite, de maneira satisfatória, entender como é possível aos sujeitos ultrapassar as relações de força. A partir deste ponto, Deleuze expressa a seguinte questão: "por que Foucault terá necessidade de outra dimensão, por que será que ele vai descobrir a subjetivação como distinta tanto do saber quanto do poder?" $\mathrm{E}$ responde:

A partir de $A$ vontade de saber, Foucault tem cada vez mais o sentimento de estar se fechando nas relações de poder. $\mathrm{E}$ por mais que invoque pontos de resistência como contraposição aos focos de poder, de onde vêm essas resistências? Foucault se pergunta: como transpor a linha, como ultrapassar as próprias relações de força? Ou será que estamos condenados a um face a face com o poder, seja detendo-o, seja estando submetidos a ele? (DELEUZE, 1992, p. 122-123).

Deleuze acredita que, em função dessa dificuldade - nos domínios do saber e do poder as forças não deixam espaços de fuga aos sujeitos assujeitados -, Foucault teria buscado uma "terceira dimensão", uma saída, que consiste no estudo das práticas de subjetivação, as "técnicas de si". O mais importante no fato de Foucault criar, em seu pensamento, a dimensão da subjetivação, das "técnicas de si", é que ele introduz, em suas análises, um elemento até então deixado de lado nas pesquisas referentes às ordens do saber e às relações de poder: a liberdade. Com isso, não se quer dizer que Foucault não veria espaços para a liberdade no contexto arqueológico das epistemes ou nos dispositivos de poder-saber que englobam a sexualidade, as práticas punitivas etc. Não se quer atribuir a Foucault a imagem da "jaula de ferro" tantas vezes identificada nas análises de Weber sobre o desenvolvimento do capitalismo no Ocidente. Antes disso, pretende-se apenas enxergar de que maneira atua esse princípio da liberdade que, no âmbito das pesquisas sobre os processos de subjetivação, serve como fundamento para as análises sobre o sujeito que é capaz de agir sobre si mesmo sem a influência cega das determinações internas e externas.

Certamente, a influência das determinações externas deve ser, aqui, melhor considerada. Primeiro, porque as técnicas do eu são históricas e variam com a história. Segundo, porque as técnicas de dominação compõem-se com as técnicas do eu no processo de subjetivação. Quem nos dá a razão é Frédéric Gros, editor do curso ministrado por Foucault no Collège de France em 1982, intitulado A hermenêutica do sujeito: 
Ora, o que constitui o sujeito numa relação consigo determinada são justamente técnicas de si historicamente referenciáveis, que se compõem com técnicas de dominação, também elas historicamente datáveis. De resto, o indivíduo-sujeito emerge tão-somente no cruzamento entre uma técnica de dominação e uma técnica de si. Ele é a dobra dos processos de subjetivação sobre os procedimentos de sujeição, segundo duplicações, ao sabor da história, que mais ou menos se recobrem ("Situação do Curso", in: FOUCAULT, 1982, p. 637).

A argumentação de Frédéric Gros parece contradizer Deleuze quando este afirma, na citação anterior, que, no "processo de subjetivação", se trata "de uma relação da força consigo (ao passo que o poder era a relação da força com outras forças)...". Na verdade, o que está em jogo, para além de saber se a força, que sai de si, na relação consigo, compõe com outras forças ou apenas dobra-se sobre si mesma, é que essa força é ela mesma indeterminada. Ela não é da ordem do saber nem do poder. Apesar de investir em "técnicas de si historicamente referenciáveis", tal como foi citado por Gros (1982), a força mesma só constitui-se em parâmetro de resistência aos jogos de poder e saber na medida em que é determinada por indivíduos historicamente constituídos pelos mesmos jogos de poder e saber. Vê-se, pois, como se faz necessário esse "para além" das forças que nos atravessam quando a constituição do sujeito do cuidado de si está em jogo.

\section{O sujeito do cuidado de si}

O sujeito do cuidado de si é aquele que faz voltar sobre si, num movimento livre de determinações externas e internas, suas ações e pensamentos. Essa "conversão a si" é o objetivo das práticas de si e o objeto sobre o qual se dirigem tais práticas é o EU. Segundo Foucault,

... qual é o objeto que se pode querer livremente, absolutamente e sempre? Qual é o objeto para o qual a vontade poderá ser polarizada de maneira tal que irá exercer-se sem estar determinada por coisa alguma do exterior? Qual é o objeto que a vontade poderá, em quaisquer circunstâncias, querer sempre, sem ter que modificar-se ao capricho das ocasiões e do tempo? O objeto que se pode querer livremente, sem ter que levar em conta as determinações exteriores, é evidentemente um só: o eu. (2004, p. 164).

O movimento em direção ao eu configura o domínio e a posse de si. A conquista do domínio de si não é necessariamente condicionada por determinantes externos, o que supõe a ideia de que todos os indivíduos, 
independente de posições de classe, status ou credo religioso, são potencialmente capazes de cuidar de si.

Os textos dos epicuristas e dos estóicos sobre o assunto [universalidade do princípio do cuidado de si] são numerosos e iterativos: afinal, um escravo pode ser mais livre que um homem livre se este não tiver se liberado de todos os vícios, paixões, dependências, etc., em cujo interior estivesse preso. [...] pode-se dizer que todos os indivíduos, em geral, são 'capazes': capazes de ter a prática de si próprios, capazes de exercer esta prática. Não há desqualificação a priori de determinado indivíduo por motivo de nascimento ou de status (FOUCAULT, 2004, p. 146).

E é através dessa relação consigo, ação sobre o eu, que se chega ao "status pleno e inteiro de sujeito". Em resumo, podemos afirmar que o sujeito do cuidado de si é aquele que possui vontade livre, indeterminada.

E o que significa querer livremente? Significa que se quer sem que aquilo que se quer tenha sido determinado por tal ou qual acontecimento, por tal ou qual representação, por tal ou qual inclinação. Querer livremente é querer sem qualquer determinação... (FOUCAULT, 2004, p. 163).

E, aqui, no tratamento dado ao "querer livremente", "sem qualquer determinação", percebe-se, de fato, a abertura operada no pensamento de Foucault com relação ao que observa Deleuze sobre o deslocamento em direção a novos caminhos que não levam ao confinamento representado pelas relações de poder e pelas ordens de saber:

Não é mais o domínio das regras codificadas do saber (relação entre formas), nem o das regras coercitivas do poder (relação da força com outras forças), são regras de algum modo facultativas (relação a si): o melhor será aquele que exercer um poder sobre si mesmo. [...] É isso a subjetivação: dar uma curvatura à linha, fazer com que ela retorne sobre si mesma, ou que a força afete a si mesma (DELEUZE, 1992, p. 141).

A palavra grifada no texto de Deleuze representa o elemento novo que aparece ao lado das determinações do saber e do poder: são as "regras facultativas", que surgem de um mesmo plano donde vêm as regras "codificadas do saber" e as regras "coercitivas do poder". Esse plano comum torna possíveis as relações de poder/saber e a liberdade na medida em que Foucault permite-se pensar a liberdade como condição de possibilidade da ética e do político. 


\section{A liberdade como condição de possibilidade do cuidado de si}

Foucault escreveu, em 1982, O sujeito e o poder. Este escrito, ao mesmo tempo em que ilumina a obra dos anos 70 sobre o poder, afastando o que havia de penumbra em torno da possibilidade de resistência frente às relações de poder tal como foram trabalhadas em Vigiar e Punir e A vontade de saber, aponta para o período da obra do autor que muitos denominam "o terceiro Foucault". Este "último Foucault", o Foucault da ética, aparece a partir deste trabalho que expõe, num plano conceitual, a maneira como se estruturam as relações entre poder e liberdade e o que constitui, de fato, uma relação de poder. Para o autor, as relações de poder consistem em "ações que incidem sobre ações", ou melhor,

... a power relationship can only be articulated on the basis of two elements which are each indispensable if it is really to be a power relationship: that 'the other' (the one over whom power is exercised) be thoroughly recognized and maintained to the very end as a person who acts; and that, faced with a relationship of power, a whole field of responses, reactions, results, and possible inventions may open up. (FOUCAULT, 1982, p. 220).

As relações de poder consistem num exercício sobre ações de um indivíduo ou um grupo de indivíduos com o objetivo de dirigir tais ações para um fim determinado. Essa concepção de poder permite a Foucault pensar as relações de poder em seu aspecto positivo, como um mecanismo gerador de ações e produtor de realidades, comportamentos, saberes etc. Por exemplo, na História da Sexualidade (1999), vemos como o poder atua no sentido de incitar desejos, gestos, comportamentos e, enfim, na produção de uma verdade sobre os sujeitos. Essa verdade participa do processo de constituição da scientia sexualis:

... em ruptura com as tradições da ars erótica, nossa sociedade constituiu uma scientia sexualis. Mais precisamente, atribuiu-se a tarefa de produzir discursos verdadeiros sobre o sexo, e isto tentando ajustar, não sem dificuldade, o antigo procedimento da confissão às regras do discurso científico. A scientia sexualis, desenvolvida a partir do século XIX, paradoxalmente, guarda como núcleo o singular rito da confissão obrigatória e exaustiva, que constitui, no Ocidente cristão, a primeira técnica para produzir a verdade do sexo. [...] Nós dizemos a sua verdade, decifrando o que dela ele [o sexo] nos diz; e ele nos diz a nossa, liberando o que estava oculto. Foi nesse jogo que se constituiu, lentamente, desde a vários séculos, um saber do sujeito... (FOUCAULT, 1999, p. 66).

Por outro lado, pensar o poder como um meio para incitar e produzir comportamentos obriga Foucault a excluir as práticas fundadas sobre 
coerção extrema do âmbito das relações de poder, onde ao indivíduo ou grupos de indivíduos coagidos não são dadas escolhas de ação. Na perspectiva lançada por Foucault, tais práticas não são da ordem do poder, pois se encontram reduzidas a um constrangimento físico. A relação necessária entre o poder como um operador sobre ações e o campo de possibilidades abertas ao indivíduo leva Foucault a definir a liberdade dos sujeitos como condição (no sentido de suporte) e précondição (condição de possibilidade) ao exercício do poder:

When one defines the exercise of power as a mode of action upon the actions of others, when one characterizes these actions by the government of men by other men - in the broadest sense of the term - one includes an important element: freedom. Power is exercised only over free subjects, and only insofar as they are free. By this we mean individual or collective subjects who are faced with a field of possibilities in which several ways of behaving, several reactions and diverse comportments may be realized. Where the determining factors saturate the whole there is no relationship of power; slavery is not a power relationship when man is in chains. (In this case it is a question of a physical relationship of constraint). Consequently, there is no face to face confrontation of power and freedom which is mutually exclusive (freedom disappears everywhere power is exercised), but a much more complicated interplay. In this game freedom may well appear as the condition for the exercise of power (at the same time its precondition, since freedom must exist for power to be exerted, and also its permanent support, since without the possibility of recalcitrance, power would be equivalent to a physical determination) (FOUCAULT, 1982, p. 221).

Depois de verificar tão íntima relação entre o poder e a liberdade, Foucault afirma, com tranquilidade, nesse mesmo texto, que uma "sociedade sem relações de poder somente pode ser uma abstração" (1982, p. 223). Isso não significa que não haja liberdade, pois esta não se encontra num confronto "face a face" com o poder, tal como num jogo de soma zero. Ora, se há poder, há a possibilidade de resistência aberta aos sujeitos assujeitados. Segundo as belas palavras de Rajchman (1993), num texto em que trabalha a ética de Foucault como potência crítica de seu pensamento:

'Quem somos', num dado momento e lugar, embora historicamente 'determinado', nunca é, ainda assim, historicamente 'exigido'. Nossa liberdade reside na contingência de nossa determinação histórica; e assim, nossa existência é sempre dotada da 'possibilidade de novas formas de comunidade, coexistência e prazer...' (RAJCHMAN, 1993, p. 116).

A ética do cuidado de si situa-se no plano contingente aberto pelas determinações históricas. A relação consigo, livre, indeterminada, só é 
possível porque um campo de possibilidades é inerente às relações de poder/saber. A relação necessária que estabelece Foucault entre o poder e o campo aberto de possibilidades aos sujeitos sugere que estes devem ser livres para que seja possível tanto a ética como a política.

\section{Conclusão}

O estatuto da liberdade, que se afirma como pré-condição e condição para o exercício do poder, estende-se ao campo das praticas de si, pois só é possível escapar às determinações exteriores se uma liberdade última permite a sua inflexão, a sua anulação e uma possibilidade de resistência aos sujeitos. As práticas de si configuram-se como resistência às determinações estruturadas em subjetividades subjugadas. $\mathrm{E}$ a preocupação de Foucault com essas práticas não sugere uma volta aos gregos nem a busca de uma subjetividade fundamental, mas a ampliação do campo de possibilidades de vida numa "atitude crítica" referida a uma filosofia comprometida com o presente. As práticas de si não estão confinadas a uma identidade ou momento histórico. Como afirma Deleuze,

... processos de subjetivação são inteiramente variáveis, conforme as épocas, e se fazem segundo regras muito diferentes. Eles são tanto mais variáveis já que a todo o momento o poder não para de recuperá-los e de submetê-los às relações de força, a menos que renasçam inventando novos modos, indefinidamente. (1992, p. 123).

A subjetivação (relação consigo) diferencia-se dos processos de individuação, que consistem na construção de subjetividades modeladas pelas relações de poder e de saber. Por exemplo, as classificações que giram em torno de normas construídas pelo saber médico veiculam individualidades confinadas a estruturas de poder e saber. Ao apontar quais indivíduos são doentes e quais são saudáveis, todo um conjunto de determinações, que incidem na relação que esses sujeitos estabelecem consigo, é posto em jogo. Para Foucault, a exploração de novas possibilidades de autorrelacionamento abre-se no processo de subjetivação. Segundo a leitura de Rajchman,

Nossa 'subjetividade' não é uma 'individualidade', uma unidade indivisível em que situemos nossa identidade; e não é uma 'particularidade' ou a exemplificação de uma natureza comum. Não é uma coisa única, e há tantas 'subjetividades' quantas são as formas aceitas de autorrelacionamento. Cada um de nós pode ter mais de um tipo de subjetividade, mais de um tipo de ser social. (1993, p. 118) 
Ora, ao operar a distinção entre "subjetividade" e "individualidade", de acordo com Rajchman, Foucault atribui ao cuidado de si um papel crítico cuja função é questionar as identidades pré-fabricadas e a supremacia dos códigos morais, que são da ordem do saber e do poder. Esse ato de subjetivar-se, Foucault inscreve-o no domínio da ética, que se opõe, portanto, à moral. Como sugere Deleuze, o "que conta, para Foucault, é que a subjetivação se distingue de toda moral, de todo código moral: ela é ética e estética, por oposição à moral que participa do saber e do poder" (1992, p. 142).

Não haveria espaço para a subjetivação e, consequentemente, para "os jogos de verdade na relação de si para si e a constituição de si mesmo como sujeito" (FOUCAULT, 1984, p.11), se as determinações externas não deixassem uma brecha de fuga aos sujeitos quando estes são orientados pelos dispositivos de saber/poder a assumir certa relação consigo. A constituição do sujeito do cuidado de si passa, portanto, pela pressuposição de uma categoria a priori, a liberdade que, necessariamente, escapa às relações de poder e aos determinismos do saber. E é por isso que se pode comparar, em épocas distintas, se sujeitos coletivos ou individuais são ou não mais livres do que outros, pois à sombra da história reside aquilo que a escapa, ou seja, a sua contingência.

\section{Referências}

DELEUZE, Gilles. Conversações 1972-1990. Rio de Janeiro: Ed. 34, 1992.

FOUCAULT, Michel. Subject and Power. In: DREYFUSS, H.; RABINOW P. Beyond structuralism and hermeneutics. Brighton: The Harvester Press, 1982. $\overline{\text { de saber. }}$

. História da sexualidade. Rio de Janeiro: Ed. Graal, 1999. Vol 1 - A vontade A hermenêutica do sujeito. São Paulo: Martins Fontes, 2004.

GROS, Frédéric. Situação do curso. In: FOUCAULT, M. A hermenêutica do sujeito. São Paulo: Martins Fontes, 2004.

RAJCHMAN, John. Eros e verdade: Lacan, Foucault e a questão da ética. Rio de Janeiro: Jorge Zahar, 1993. 